\title{
The Game Analysis of Insurance Funds to Participate in the PPP Earnings Distribution
}

\author{
Zhai Yigang \\ School of Public Finance and Tax, Central University of Finance and Economics, Beijing, China \\ Email address: \\ 150010098@qq.com \\ To cite this article: \\ Zhai Yigang. The Game Analysis of Insurance Funds to Participate in the PPP Earnings Distribution. International Journal of Business and \\ Economics Research. Vol. 8, No. 6, 2019, pp. 452-457. doi: 10.11648/j.ijber.20190806.25
}

Received: October 31, 2019; Accepted: November 28, 2019; Published: December 10, 2019

\begin{abstract}
The long-term and stable nature of insurance funds and the long-term demand of PPP projects for funds are naturally in line with each other. In the future, there is still great potential for insurance funds to deeply participate in PPP projects and serve the development of real economy. According to the current development rate, the available scale of insurance funds during the 13th five-year plan period will reach 20 trillion yuan, which not only provides sufficient sources of funds for insurance funds to participate in PPP projects. At the same time, it also creates a good condition for the insurance fund to conduct financing and service innovation in combination with the characteristics of PPP projects. The participation of insurance funds in PPP projects has become an important issue in the current development, but the earnings in the cooperation between the two sides need to be fully discussed and analyzed to avoid a series of problems caused by unreasonable distribution. Based on the current developing situation of insurance funds participating in PPP projects, this paper conducts two-party game analysis and three-party game analysis according to the classification of complete information condition and incomplete information condition. Through conditional assumption, model establishment and solution, the reasonable proportion of insurance enterprises, public sectors and project companies under different circumstances is obtained, and policy suggestions on promoting insurance funds to participate in PPP model are put forward.
\end{abstract}

Keywords: Insurance Fund, The PPP, Complete Information Game, Incomplete Information Game

\section{Introduction}

PPP refers to the cooperation form between the public sector and insurance enterprises, which is a new model formed after the exploration of BOT and other models. [1] It aims to achieve the expected effects of both sides through the cooperation of the government or the public and private sectors to jointly invest in infrastructure construction projects. The private sector here, on the macro level, can be immediately divided into most non-public sectors, such as individuals, households, private for-profit enterprises and private non-profit organizations. Insurance funds refer to the capital, reserve funds, undistributed profits, various reserves and other funds of insurance companies (holding companies) and insurance companies, denominated in local and foreign currencies. According to the source, capital, accumulation fund and undistributed profits are self-owned funds, while reserves are liabilities. Other funds are also important sources of insurance funds, often borrowed or consolidated based on demand and allocation. Therefore, the insurance fund can plan a role as leverage and participate in capital investment as a private sector. [2]

PPP model has gradually become one of the main promotion models in the field of infrastructure construction in China. However, the long-term fund of PPP projects is very limited, and the existing fund scale can hardly meet the demand of a large number of PPP projects in the future. Although there is support from public finance funds in the field of public infrastructure construction, the capacity and responsibility of the public sector are limited, so it cannot completely rely on the power of the public sector. At the same time, insurance capital has limitations in terms of investment channels. While policies are moderately adjusted, infrastructure construction can be regarded as one of the alternative ways for investment. Since the state council implemented the PPP model in infrastructure and public service sectors, major changes have taken place in the investment and financing model of infrastructure. PPP has 
been upgraded to the strategic height of national development and is the main mode of infrastructure investment and financing in the future. At the same time, the distribution of insurance funds themselves is also increasing, and investment channels have become more diversified. [3] Generally, PPP projects are characterized by large scale and relatively stable income, which are in line with insurance funds and investment demands. According to data released by the China insurance asset management association, from January to December 2018, 26 insurance asset management companies registered a total of 213 debt investment plans and equity investment plans, with a total registered amount of 454.726 billion yuan. Among them, 121 creditor's rights investment plans for infrastructure projects, with a registered scale of 294.086 billion yuan; There were 89 creditor's rights investment plans for real estate, with a registered size of 124.54 billion yuan; Three equity investment plans, with a registered size of 36.10 billion yuan. Data by the end of December 2018 shows that the insurance asset management industry has initiated 1,056 creditor's rights and equity investment plans of various kinds, with a total filing (registration) volume of 2,530.140 billion yuan. Such a large capital scale can meet the funding needs of PPP projects.

On November 31, 2018, the state council issued "guiding opinions on improving underdeveloped areas in infrastructure field" (SCO [2018] 101), making an increase in financial support to the project under construction and supplementary short projects of major projects. It aimed to give full play to the advantages of long term investment, such as insurance funds, through debt, equity, stock bonds, funds, and other forms, and was positive for construction projects and major projects to provide financing. The development and reform commission, the ministry of finance, the people's bank of China and the China securities regulatory commission are responsible for the responsibilities. Local people's governments at all levels are responsible. Policy support for insurance funds to participate in infrastructure construction was strengthened. Therefore, it is necessary to sort out the use of PPP model and insurance funds and find a new direction for the cooperation and development of insurance funds and PPP projects.

\section{Method}

\subsection{Under the Condition of Complete Information, Two Parties Play: Public Sector and Insurance Enterprise}

According to the game principle, under the condition of complete information, the earing distribution process of the two sides of the game can be regarded as the bargaining process between the government and the insurance company. Here, the Nash solution to the bargaining problem can be used to obtain the optimal state of income distribution. [4]

1. Assumptions

In order to determine the benefit distribution plan of PPP projects, the following assumptions are made before establishing the model:
Hypothesis 1: consider only the direct benefits of capital and capital generated by the sale of projects by the government and insurance companies.

Hypothesis 2: according to the investment amount of the insurance enterprise capital, the government promises to provide a fixed investment return for the insurance enterprise capital.

Hypothesis 3: whatever the outcome of the negotiations, cooperation will yield more benefits than non-cooperation.

The game process: before a final agreement is reached, the public sector and the insurance asset management company will haggle over the return on investment for a certain amount of investment.

2. Model

Assume that the total return rate of the project over its life cycle is R. Vector Ii represents the possible allocation scheme, and vector $(\mathrm{r} 1, \mathrm{r} 2)$ represents the gain obtained by both parties from the allocation scheme. It should be noted that the government and insurance companies have different positions in the bargaining process. Therefore, the game discount factorai $(\mathrm{i}=1,2)$ between the two parties is different. In the negotiation process with insurance companies, the government's position is absolutely higher than that of insurance companies. The discount factor negotiated must be greater than that of the insurance company. [5]

Game process derivation:

First, the government proposes plan I1, and the return on investment of the insurance company is I1. If the insurance company accepts this plan, the benefit distribution negotiation will be terminated, and the benefits of both parties are as follows:

Public sector gains: r11=R-I1

Earnings of insurance enterprises: r21=I1

Second, if the insurance company rejects the benefit distribution plan offered by the public sector, the insurance company will propose benefit distribution plan I2, which will be returned by the public sector. If the public sector agrees to the new distribution plan, the negotiation will be terminated. The benefits of both parties are as follows:

Public sector revenue: $\mathrm{r} 12=\alpha 1$ (R-I2)

Insurance earnings: $r 22=\alpha 2 \mathrm{I} 2$

Third, if the public sector does not agree with the new allocation plan, the public sector will propose the new allocation plan. If the insurance company agrees to the plan, the negotiation will be terminated and the benefits for both parties will be:

$$
\begin{gathered}
\text { Public sector revenue: } r 13=\alpha 12 \quad(\mathrm{R}-\mathrm{I} 3) \\
\text { Insurance earnings: } \mathrm{r} 23=\alpha 2 \mathrm{I} 3
\end{gathered}
$$

The game process is carried out successively until the end of the negotiation.

3. Solution 
According to the inverse induction method, we assume that the second step is the inverse point to solve, namely, $\mathrm{r} 12=\mathrm{r} 22$.

$$
\mathrm{I}_{1}=\alpha_{2} \mathrm{I}_{2} \text {. }
$$

At this point, the government's revenue has also changed, which can be set to $r 11: r_{11}=\mathrm{R}-\alpha_{2} \mathrm{I}_{2}$

$$
\mathrm{r} 11-\mathrm{r} 12=\mathrm{R}-\alpha 2 \mathrm{I} 2-(\alpha 1 \mathrm{R}-\alpha 2 \mathrm{I} 2)=\mathrm{R}(1-\alpha 2)+\mathrm{I} 2(\alpha 1-\alpha 2)
$$

Because $\alpha 1>\alpha 2$, then $r 11>$ r12. It means that both parties have reached an agreement in the first round. At this time, the benefits of both parties are:

$$
\begin{aligned}
& \text { Public sector benefit: } r 1=\alpha 1 \mathrm{R}(\alpha 1+\alpha 2)-1 \\
& \text { Insurance earnings: } r 2=\alpha 2 \mathrm{R}(\alpha 1+\alpha 2)-1
\end{aligned}
$$

Therefore, the income distribution ratio of the public sector and insurance companies is obtained.

\subsection{Three-party Game Under the Condition of Complete Information: Insurance Enterprises, Public Departments and Project Companies}

Under the condition of complete information, the three-party game can be analyzed with the "insider" model. [6]"Insiders" refers to the main body of the game as insiders, within a game insiders have mutual influencements among one another, with the increase of the game rounds, the game will eventually reach an equilibrium. In the analysis, the subjects include insurance enterprises, public departments and project companies. Therefore, there are three insiders in this insider model, which are simply identified as insiders 1 , insiders 2 and insiders 3 . In the game model, all insiders represent their own interests. It should be noted that before the analysis of insider model, we assume that all insiders can directly express the interest demands of all parties and exert influence on other insiders. And the ultimate goal of all insiders is to maximize their own interests.

The deterrence relationship between the various games is shown in the figure below, indicating that if no agreement is reached, the damage factor of the game player $\mathrm{i}(\mathrm{i}=1,2,3)$ against the insider $\mathrm{j}(\mathrm{j}=1,2,3)$. The smaller $\delta \mathrm{ij}$, the more loss the participant in the model will make to the person $\mathrm{j}$ in the model, and vice versa.

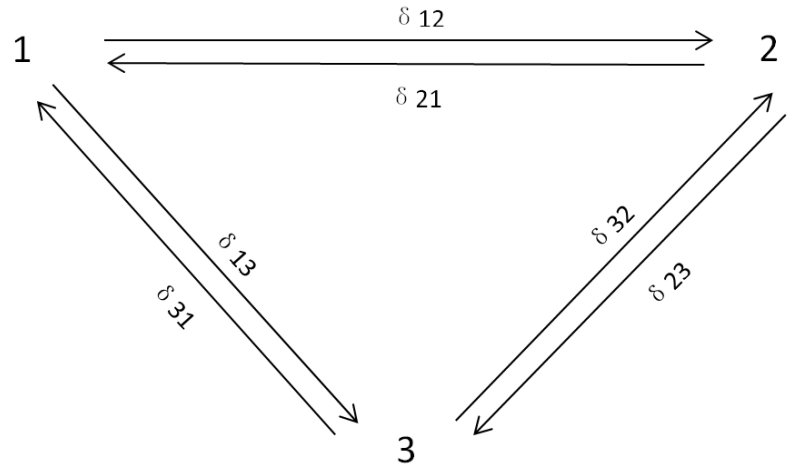

Figure 1. Three-party game under the condition of complete information.
Assuming that both insider 1 and insider 2 have incomplete information, insider 1 has high bargaining power type $1 \mathrm{H}$ and low bargaining power type $1 \mathrm{~L}$. The prior probability is $\mathrm{p}$ and $1-\mathrm{p}$ respectively, and the impairment factors of insider 2 and insider 3 are private information. In type $1 \mathrm{H}, \delta_{12}{ }^{\mathrm{L}}$ and $\delta_{13}{ }^{\mathrm{L}}\left(\delta_{12}{ }^{\mathrm{L}} \leq \delta_{12}, \delta_{13}{ }^{\mathrm{L}} \leq \delta_{13}\right)$ will be the damage factors of group 1 to 2 and group 1 to 3 respectively. In type $1 \mathrm{~L}, \delta_{12}{ }^{\mathrm{H}}$ and $\delta_{13}{ }^{\mathrm{H}}\left(\delta_{12}{ }^{\mathrm{H}} \geq \delta_{12}, \delta_{13}{ }^{\mathrm{H}} \geq \delta_{13}\right)$ will be the damage factors of group 1 to 2 and group 1 to 3 respectively. Insider 2 has high bargaining power $2 \mathrm{H}$ type and low bargaining power $2 \mathrm{~L}$ type, and their prior probabilities are $\mathrm{q}$ and $1-\mathrm{q}$ respectively. The loss factors of insider 2 and local 3 are private information. In type $2 \mathrm{H}$, the damage factors will be $\delta_{21}{ }^{\mathrm{L}}$ and $\delta_{23}{ }^{\mathrm{L}}\left(\delta_{21}{ }^{\mathrm{L}} \leq \delta_{21}, \delta_{23}{ }^{\mathrm{L}} \leq \delta_{23}\right)$. In type $2 \mathrm{~L}$, conversion factors will be $\delta_{21}{ }^{\mathrm{H}}$ and $\delta_{23}{ }^{\mathrm{H}}\left(\delta_{21}{ }^{\mathrm{H}} \geq \delta_{21}, \delta_{23}{ }^{\mathrm{H}} \geq \delta_{23}\right)$. Insider 3 has complete information, and the damage factor of insider 1 and insider 2 is public knowledge of $\delta 31$ and $\delta 32$ respectively.

Assuming that the game is an in-game 3, they can be treated as in-game and as members of the $\{2,3\}$ union bargaining with each other. Insiders 1 proposals are $(\alpha, 1-\alpha)$ $(\beta, 1-\beta)(\eta, 1-\eta)(\lambda, 1-\lambda)$, including:

$$
\begin{gathered}
\alpha=\left(1-\delta_{23,1}{ }^{\mathrm{L}}\right) /\left(1-\delta_{1,23}{ }^{\mathrm{L}} \delta_{23,1}{ }^{\mathrm{L}}\right), \\
\beta=\left(1-\delta_{23,1}{ }^{\mathrm{L}}\right) /\left(1-\delta_{1,23}{ }^{\mathrm{H}} \delta_{23,1}{ }^{\mathrm{L}}\right), \\
\eta=\left(1-\delta_{23,1}{ }^{\mathrm{H}}\right) /\left(1-\delta_{1,23}{ }^{\mathrm{L}} \delta_{23,1}{ }^{\mathrm{H}}\right), \\
\lambda=\left(1-\delta_{23,1}{ }^{\mathrm{H}}\right) /\left(1-\delta_{1,23}{ }^{\mathrm{H}} \delta_{23,1}{ }^{\mathrm{H}}\right)
\end{gathered}
$$

Suppose the posterior probability of group $1 \mathrm{H}$ is $\mathrm{p} 1, \mathrm{p} 2, \mathrm{p} 3$ and $\mathrm{p} 4$ respectively after insider 1 proposes each of the above four schemes.

When the insider 1 were group $1 \mathrm{H}$ and group $1 \mathrm{~L}$, analysis was carried out by the above similar methods and it can be known that:

1) For group $1 \mathrm{H}$ insider 1 , when $\mathrm{p} 2>\mathrm{p} 2 \mathrm{H}$, he proposed the scheme $(\beta, 1-\beta)$, which was accepted by $\{2,3\}$; When $\mathrm{p} 2$ $<$ p2H and $\mathrm{q} \geq \mathrm{qH}$, he proposed the scheme $(\alpha, 1-\alpha)$, which was accepted by $\{2,3\}$. When $\mathrm{p} 2<\mathrm{p} 2 \mathrm{H}$ and $\mathrm{q}<\mathrm{qH}$, he will put forward the scheme $(\beta, 1-\beta)$, which is accepted by the $\{2$, $3\}$ in group $2 \mathrm{~L}$, but rejected by the $\{2,3\}$ in group $2 \mathrm{H}$, at which time conflicts may occur.

2) For group $1 \mathrm{~L}$ insider 1 , when $\mathrm{p} 2 \geq \mathrm{p} 2 \mathrm{H}$, he will propose the scheme $(\beta, 1-\beta)$, which is accepted by $\{2,3\}$ alliance; When $\mathrm{p} 2<\mathrm{p} 2 \mathrm{H}$ and $\mathrm{q} \geq \mathrm{qH}$, he will propose the scheme $(\alpha$, $1-\alpha)$, which is accepted by $\{2,3\}$; When $\mathrm{p} 2<\mathrm{p} 2 \mathrm{H}$ and $\mathrm{q} \leq \mathrm{qL}$, he will put forward the scheme $(\beta, 1-\beta)$, which is accepted by the $\{2,3\}$ in group $2 \mathrm{~L}$, but rejected by the $\{2,3\}$ in group $2 \mathrm{H}$. At this time, conflicts may occur. When $\mathrm{p} 2<\mathrm{p} 2 \mathrm{H}$ and $\mathrm{qL}<\mathrm{q}$ $<\mathrm{qH}$, if insiders proposed $(\eta, 1-\eta)$ or $(\lambda, 1-\lambda)$, then conflict do not occur, but the proposed solution $(\beta, 1-\beta)$, may cause a conflict.

In the insider model analysis, the public sector, insurance companies and project companies have equal status, so they can influence each other. Under the condition of incomplete information, the information mastery degree of the three is different. When the public sector and the project company are under the condition of incomplete information, neither of them 
will be approved by the insurance company. Similarly, any proposal proposed by either party under the price adjustment with incomplete information is difficult to be approved by the third party. In this case, conflict is highly likely. Therefore, in the insider's setting, it is easy to produce the conflict of interest distribution in the three-party bargaining game under the condition of complete information. [7]

\subsection{Two-party Game Under the Condition of Incomplete Information: Public Sector and Insurance Enterprise}

\section{Basic assumptions}

The above interest game model is a simulation analysis under the condition of complete information. There are many incomplete information conditions in real life. [8] To play a bargaining game under the condition of incomplete information, the following premise can be made:

Hypothesis 1: the bargaining game is carried out under the condition of incomplete information. That is, the information between the public sector and insurance companies is not equal. Generally speaking, the public sector has more information, while the insurance companies have less information.

Hypothesis 2: the public sector tends to cooperate with insurance companies on the premise of normal interests.

Hypothesis 3: insurance companies in the process of choice of the PPP projects, needs to pay a certain cost, as $v$. As negotiations continue, the risks (or costs) borne by both sides of the game will continue to increase.

\section{Model building}

First of all, it is assumed that such a rule is set in the negotiation: first, the public sector proposes a certain proportion of profit distribution, and insurance companies can accept or reject it; If the insurance company accepts, the game is over; if the insurance company rejects, the insurance company resubmits the allocation plan, and the public sector chooses whether to accept this cycle until one party accepts it. If the plan is rejected, the rejected plan will no longer be relevant to future negotiations. [9]

If $\mathrm{s}$ represents the share of the public sector and 1-s represents the share of the insurance company, where $(0 \leq s \leq 1)$, if the discount factor of the public sector and the insurance company is $\delta 1$ and $\delta 2(0<\delta<1]$, it can be regarded as the shutdown cost and interest loss (sunk cost). So let's say that the game ends in time $t$, and $t$ is the time of public sector bid, and the public sector returns $\pi_{0}=\delta_{1}{ }^{\mathrm{t}-1} \mathrm{~S}_{\mathrm{t}}$, and the discount rate of insurance company profit is $\pi \mathrm{s}=\delta 2 \mathrm{t}-1 \mathrm{St}$. This repeating game can be described as follows:

In the first stage, the public sector proposes that its expected revenue ratio is $\mathrm{S} 1$. In the two-party profit game, the profit ratio that an insurance company can obtain is 1-S1. If both parties agree to such a plan, then the game is over, with public sector earnings recorded as $\mathrm{S} 1 \pi$ and insurance company earnings recorded as $\left(1-\mathrm{S}_{1}\right) \pi$. If one party (generally refers to the insurance company) does not agree to this plan, then this plan is invalid and the negotiation will enter into the second stage.

In the second stage, the allocation plan proposed by the insurance company is the proportion S2 of the public sector, so the proportion of benefits obtained by the insurance company is $1-S_{2}$. If both sides agree to such a plan, the game is over. The public sector gains are recorded as $\delta_{1} \mathrm{~S}_{2} \pi$, and the insurance company gains are recorded as $\delta_{2}\left(1-\mathrm{S}_{2}\right) \pi$. If one party (generally the public sector) does not agree to the plan, the plan is invalid and negotiations will enter into the third phase.

In the third stage, the public sector will bid again, that is, the proportion of public sector earnings obtained is S2, and the proportion of insurance companies' earnings obtained is $1-\mathrm{S}_{2}$. If both sides agree to the deal, the game is over, with public sector gains being marked as $\delta_{1}{ }^{2} \mathrm{~S}_{3} \pi$ and insurance companies $\delta_{2}^{2}\left(1-S_{3}\right) \pi$. If one party (generally refers to the insurance company) does not agree to this plan, then this plan is invalid and the negotiation will enter into the fourth stage.

The game process is as follows:

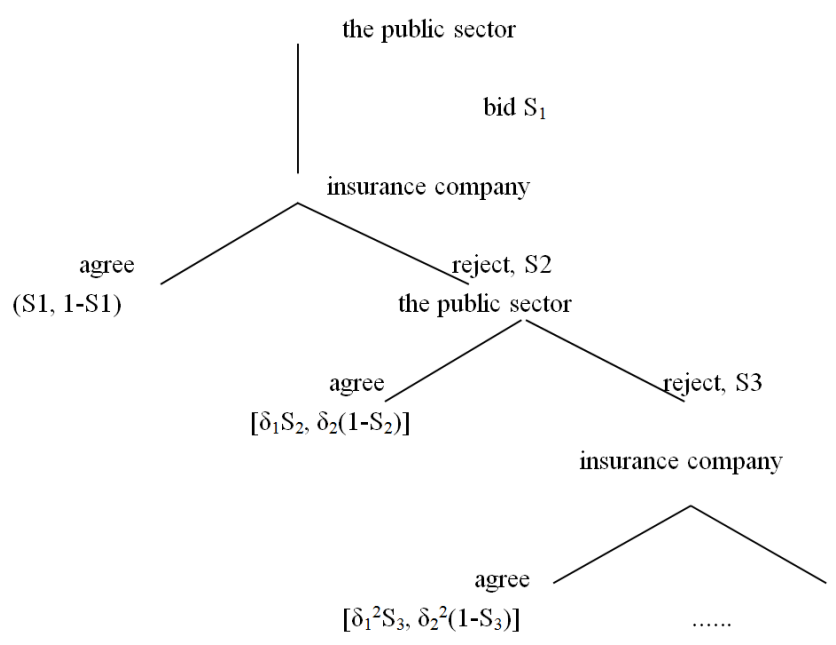

Figure 2. Two-party game under the condition of incomplete information.

In this kind of analysis of the game, the game might be going all the way around, so $\mathrm{T}$ is equal to infinity. In the theoretical analysis, it is considered that the game of infinite stage analysis can't determine the final result, so it can't be solved by inverse method. However, in the actual situation, due to the existence of objective factors such as time, the game between the two sides will not continue to be infinite as in the theoretical analysis. But in this game, the two sides may not calm down because there is no final stage. [10]

Assuming that there are only two stages, when $\mathrm{T}=2$, the insurance company proposes the allocation scheme of $\mathrm{S} 2=0$, and accepts the scheme because the public sector has no chance to bid again. If the public sector puts forward bid plan $\mathrm{S} 1$ in the first stage, the insurance company will receive $\delta_{2} \pi$ in the second stage, the insurance company will get 1-S1, and the insurance company $\left(1-\mathrm{S}_{1}\right) \pi \geq \delta_{2} \pi$, then the insurance company will accept this allocation plan. Assuming the public sector is rational, it will not give insurers more than the minimum share it will accept. So $S_{1}=1-\delta_{2}$, so the refined equilibrium is going to be $\left(1-\delta_{2}\right) \pi$ for the public sector, $\pi$ $\left(1-\delta_{2}\right)$ for the insurance industry.

Suppose $\mathrm{T}=3$. In the final stage, the public sector proposes the allocation scheme and proposes $\mathrm{S} 3=1$. Because the public 
sector gets $\pi$ units of profit in the third stage is equal to $\delta_{1} \pi$ of profit in the second stage. In other words, if the insurer bid $\mathrm{S}_{2}=\delta_{1}$ in the second stage, the public sector will gain $\delta_{1} \pi$, and the public sector will accept the plan: and because the insurer will gain $\left(1-\delta_{1}\right) \pi$ in the second stage is equal to $\delta_{2}\left(1-\delta_{1}\right) \pi$ in the first stage.

Therefore, if the public sector proposes an allocation of $1-S_{1} \geq \delta_{2}\left(1-\delta_{1}\right)$ in the first stage, the insurer will accept it. Assuming the public sector is rational, it will not give more than the minimum share it will accept, which is $1-\mathrm{S}_{1}=\delta_{2}\left(1-\delta_{1}\right)$. The subgame refinement equilibrium results in the public sector gaining is $\left[1-\delta_{2}\left(1-\delta_{1}\right)\right] \pi$ and the insurance industry gaining is $\delta_{2}\left(1-\delta_{1}\right)$. By analogy, the above method can be used to derive a simplified Nash equilibrium solution for any given subgame with $\mathrm{T}<\infty$.

\subsection{Tripartite Game Under the Condition of Incomplete Information: Insurance Company, Public Sector and Project Company [11]}

1. Basic assumptions

Assume that the fund of insurance company (money managed by the public sector) is I, the PPP project fee is $\delta \cdot \mathrm{I}$ ( $\delta$ is constant, about $1 \sim 3$ ) and the expected return is Q. Q depends mainly on the PPP project company action result $\alpha$. Random variable factor $\xi$ (depending on market risk, the PPP project investment industry status, as well as the superiority of the project, etc.). In the insurance funds to participate in the PPP projects, we will project expected income as $\mathrm{Q}$, $\mathrm{Q}=\mathrm{Q}=\alpha+\xi$, assumes that the random variable $\xi \sim\left(\mu, \sigma^{2}\right)$. The cost corresponding to the benefit is called $\mathrm{C}$, whose function is $C(\alpha)=1 / 2 \cdot c_{1} \cdot \alpha^{2}$.

Suppose that according to the contract, the share of PPP project company in expected investment return $\mathrm{Q}$ is $1-\mathrm{x}$. The public sector accounts for $\mathrm{kx}$ (the contract stipulates that the public sector is entitled to this part of income after reaching the minimum return on investment), and the insurance company accounts for $(1-\mathrm{k}) \mathrm{x}$, where the constant is called the profit distribution ratio coefficient agreed by the insurance company to stimulate the public sector. Generally 0.2 ).

Assuming that $\alpha$ is a function of stock ratio $\mathrm{x}$ and $\alpha(\mathrm{x})=\alpha \mathrm{x}$ $(\alpha>\mu)$, the effort cost of the PPP project company is $1 / 2 \cdot c_{1} \cdot \alpha^{2} \cdot x$. In venture capital operation, the public sector, as a direct investor, is mainly responsible for supervising and managing professional managers of PPP project companies. Therefore, the effort level is reflected in the monitoring effect of expected income Q and actual income $\theta \mathrm{Q}$ of PPP project companies. Where $\theta$ is the efficiency coefficient of the PPP project company's effort level. The greater the effect, the smaller the difference between the expected revenue and the actual revenue. Therefore, the effort cost of the public sector can be defined as $1 / 2 \cdot c_{2}(\mathrm{Q}-\theta \cdot \mathrm{Q})^{2}=1 / 2 \cdot \mathrm{c}_{2}(1-\theta)^{2} \cdot \mathrm{Q}^{2}$, where $\mathrm{c}_{2}$ is called the marginal cost effort factor of the public sector.

Insurance companies do not directly participate in the management and operation of venture capital, but only supervise the public sector through relevant agreements in contracts. It is assumed that the cost of supervising a risky company by an insurance company is negligible. [12]

\section{Model establishment and solution}

From the above assumptions, it can be concluded that the income functions $\mathrm{y} 1, \mathrm{y} 2$ and $\mathrm{y} 3$ of PPP project company, public sector and insurance company are respectively as follows:

$$
\begin{gathered}
\mathrm{y}_{1}=(1-\mathrm{x}) \cdot \mathrm{Q}-1 / 2 \cdot \mathrm{c}_{1} \cdot \alpha^{2}-\mathrm{I}=(1-\mathrm{x}) \cdot(\alpha \mathrm{x}+\xi)-1 / 2 \cdot \mathrm{c}_{1} \cdot \mathrm{x}^{2}-\mathrm{I} \\
\mathrm{y}_{2}=\mathrm{k} \cdot \mathrm{x} \cdot \mathrm{Q}-1 / 2 \cdot \mathrm{c}_{2} \cdot(1-\theta)^{2} \cdot \mathrm{Q}^{2}-(1-\delta) \cdot \mathrm{I} \\
=\mathrm{k} \cdot \mathrm{x}(\alpha \mathrm{x}+\xi)-1 / 2 \cdot \mathrm{c}_{2} \cdot(1-\theta)^{2} \cdot(\alpha \mathrm{x}+\xi)^{2}-(1-\delta) \cdot \mathrm{I} \\
\mathrm{y}_{3}=(1-\mathrm{k}) \cdot \mathrm{x} \cdot \mathrm{Q}-\mathrm{I}
\end{gathered}
$$

The expected value of the three-party revenue functions $y 1$, y2 and y3 can be obtained as follows:

$$
\begin{gathered}
\mathrm{E}\left(\mathrm{y}_{1}\right)=-\left(\alpha+1 / 2 \cdot \mathrm{c}_{1} \cdot \alpha^{2}\right) \mathrm{x}^{2}+(\alpha-\mu) \mathrm{x}+\mu-1 \\
\mathrm{E}\left(\mathrm{y}_{2}\right)=\left(\alpha \mathrm{k}-1 / 2 \cdot \mathrm{c}_{2} \alpha^{2}(1-\theta)^{2}\right) \mathrm{x}^{2}+ \\
\left(\mu \mathrm{k}-\mathrm{c}_{2} \alpha \mu(1-\theta)^{2}\right) \mathrm{x}-1 / 2 \cdot \mathrm{c}_{2}(1-\theta)^{2}\left(\mu^{2}+\sigma^{2}\right)-(1-\delta) \mathrm{I} \\
\mathrm{E}\left(\mathrm{y}_{3}\right)=(1-\mathrm{k}) \cdot \alpha \cdot \mathrm{x}^{2}+\mu \cdot(1-\mathrm{k}) \cdot \mathrm{x}-\mathrm{I} \\
\frac{\partial \mathrm{E}(\mathrm{y} 1)}{\partial \mathrm{x}}=-(2 \alpha+\mathrm{c} 1 \cdot \alpha 2)+(\alpha-\mu) \\
\frac{\partial \mathrm{E}(\mathrm{y} 2)}{\partial \mathrm{x}}=\left(2 \alpha \mathrm{k}-\mathrm{c}_{2} \alpha^{2}(1-\theta)^{2} \times\left(\mu \mathrm{k}-\mathrm{c}_{2} \alpha \mu(1-\theta)^{2}\right)\right. \\
\frac{\partial \mathrm{E}(\mathrm{y} 3)}{\partial \mathrm{x}}=2(1-\mathrm{k}) \cdot \alpha \mathrm{x}+\mu \cdot(1-\mathrm{k}) \\
\frac{\partial \mathrm{E}\left(\mathrm{y}_{1}\right)}{\partial x}=0, \mathrm{x}_{1} \frac{\alpha-\mu}{\alpha\left(2+\mathrm{c}_{1} \alpha\right)} \\
\frac{\partial \mathrm{E}(\mathrm{y} 2)}{\partial x}=0, \mathrm{x}_{1}=\frac{\mu\left(\mathrm{c}_{2} \alpha(1-\theta)^{2}-\mathrm{k}\right)}{\alpha\left(2 \mathrm{k}+\mathrm{c}_{2} \alpha(1-\theta)^{2}\right)}
\end{gathered}
$$

It can be seen that insurance companies do not directly participate in the management and operation of venture capital, but only supervise the public sector through relevant agreements in the contract. [13] Therefore, it is assumed that the regulatory costs of insurance companies on PPP project companies are negligible. $[14,15]$

\section{Result and Discussion}

In conclusion, two-party game and three-party game models are compared by analyzing the bargaining models under incomplete information and complete information. [16] Before the establishment and solution of the interest game model, the basic assumption of the game model is that both parties or three parties do not want the negotiation to break down. [17] Meanwhile, in the solution, the inverse method is used to solve the risk sharing and interest distribution ratio of each participant and draw the following conclusions:

In the interest game model: generally speaking, due to the long time of large-scale infrastructure construction, complex procedures, long period of capital returning, and difficulty to predict risks, the public sector, in a sense, bears relatively high risks for the expected income commitment for insurance companies. [18] That is, when the public sector promises the 
corresponding benefits to the insurance enterprises, the public sector bears the objective risks existing in the project itself. [19] Therefore, when the income commitment is given to insurance companies, the income ratio should be set carefully and in line with the reality, and a higher return on investment should not be promised due to insurance funds, which indirectly increases the risk of the public sector. [20] In response, the public sector could set floating rates below the risk threshold to attracting insurance capital. On the one hand, it can promote the participation of insurance funds in PPP project construction; on the other hand, it can get the risk of public sector within a reasonable range.

\section{Conclusion}

On the whole, in order to promote the participation of insurance funds in PPP projects, 4 solutions should be taken: more participation modes, strengthening policy guidance, risk prevention and optimizing allocation mechanism. [21] First, find more ways to enrich insurance funds to participate in PPP projects. The participation of insurance funds has a positive impact on the public sector to achieve social goals and the development of insurance enterprises. [22] Therefore, insurance funds can achieve cooperation by participating in national infrastructure construction, setting up equity investment funds, participating in local government bonds and local financing platforms, etc. Second, we will strengthen policy guidance. In the cooperation between insurance funds and PPP projects, policy guidance and support is an important prerequisite for their cooperation. Therefore, the insurance fund can be attracted through tax policy, department coordination and service optimization, and a more mature operation mechanism is needed to assist the insurance fund to participate in the PPP model. Third, we will strengthen risk prevention. Through the analysis of risk game model, it can be seen that risks exist objectively and independently, and the prevention and response of risks need the joint efforts of insurance enterprises and public sectors. In terms of risk sharing, the principle of equity should be emphasized and shared by two (or three) parties. Fourth, we will improve the income distribution mechanism. Through the analysis of the income game model, it can be seen that the interest demands of both sides of the game are needed to establish a reasonable distribution system. [23]

\section{References}

[1] Kang Jia, Jie Sun, The concept, origin, characteristics and functions of public-private partnership (PPP) [J]. Finance research, 2009.

[2] China insurance regulatory commission, Interim measures for the management of the use of insurance funds (2014).

[3] Mingsheng Yang, A historical leap in the use of new rules for insurance funds [J]. Insurance research, 2011.

[4] Xiao xiao, Game analysis of the interaction between insurance capital and capital market [J]. Insurance research, 2007.
[5] Yan Li, Research on risk sharing of infrastructure PPP model based on game theory [D]. China university of mining and technology, 2017.

[6] Yong Yuan, Shaohua Xie, Insider action research: a new methodology integrating researchers and practitioners $[\mathrm{J}]$. Research on modern distance education, 2016.

[7] Yaobin Yin, Game study of main participants in PPP project asset securitization, [D]. Chongqing technology and business university, 2016.

[8] Wei Liu, Theoretical interpretation and practical examples of PPP model [J]. Reform, 2015.

[9] Xiaoyu Li, An empirical study on the efficiency of insurance fund utilization [D]. Capital university of economics and business, 2014.

[10] Mingjing Zhao, Performance analysis of insurance capital market investment in China [D] Lanzhou business school, 2011.

[11] Hengchang Wei, Study on risk sharing of PPP urban infrastructure project based on game theory [D] Wuhan university of technology, 2011.

[12] Wenjun Sun, A study on the coordination of contract subjects under asymmetric information in large-scale construction projects [D] Xi 'an university of architecture and technology, 2011.

[13] Jiangbo Song, Research on risk investment of insurance fund [D] East China normal university, 2009.

[14] Zhou xianglian, zhang weiqin. Risk sharing of PPP project in underground comprehensive pipe gallery from the perspective of dynamic game [J]. Frontiers of social science, 2019.

[15] Xue linjing. Study on risk sharing model of integrated pipe gallery project under PPP model [D] Xi 'an university of architecture and technology, 2017.

[16] Wang ting. Research on PPP project risk sharing in underground comprehensive pipe gallery [D]: [master's thesis]. Wuhan: wuhan university, 2018.

[17] Wu wenqing. Research on infrastructure investment strategy of insurance funds [J]. Reference of economic research, 2006 (88): 18-23.

[18] Wang yu. Analysis on PPP financing of transportation infrastructure construction projects in hebei province [D]. Hebei university of economics and trade,2016.

[19] Zhou gang. Research on investment of insurance funds [D]. Capital university of economics and business, 2013.

[20] Li feifei. Research on the development of alternative investment of insurance funds in China [D].

[21] Guo guo. Problems and countermeasures of China's pension fund investment in infrastructure [D]. Southwest university of finance and economics, 2013.

[22] Cheng zhizhong, du chunyan. Feasibility analysis of investment in infrastructure of life insurance in China [J]. Investment research, 2003.

[23] Wei xuan. An overview of international experience in insurance fund investment in infrastructure [J]. Insurance research, 2014. 